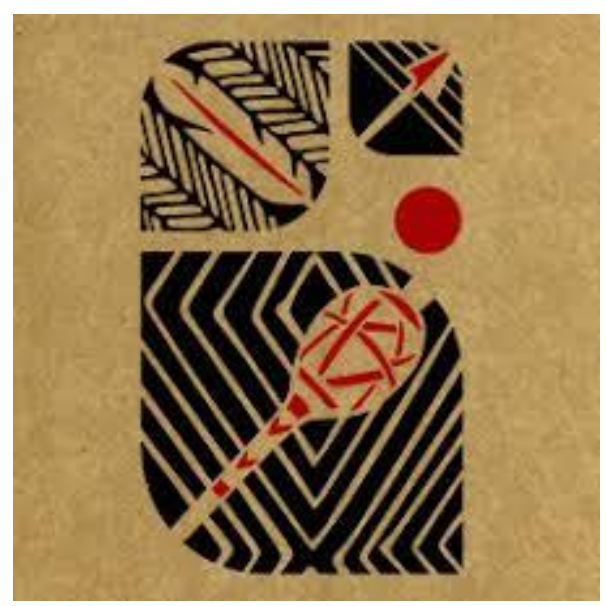

\title{
A emergência das heterogeneidades enunciativas no discurso indigenista oficial brasileiro
}

The emergence of enunciative heterogeneities in the brazilian official indigenous discourse

\author{
Sheila da Costa Mota Bispo ${ }^{1}$ \\ https://orcid.org/0000-0001-9753-5551 \\ Vânia Maria Lescano Guerra ${ }^{2}$ \\ https://orcid.org/0000-0001-8361-2106
}

\section{Resumo:}

Este trabalho objetiva problematizar emergências de heterogeneidade(s) enunciativa(s) (AUTHIER-RÉVUZ, 1990, 1998, 2004) no Documento Base, elaborado para embasar a $1^{\text {a }}$ Conferência Nacional de Política Indigenista. Alicerça-se nos estudos da AD de origem francesa e no método arquegenealógico (FOUCAULT, 2015), em sua perspectiva dicursivo-desconstrutiva (CORACINI, 2007, GUERRA, 2011). Os resultados obtidos indicam que a utilização das aspas na materialidade discursiva analisada se deu, primeiro, como recurso preventivo contra a apropriação da ideia alheia, depois pela necessidade de o sujeito enunciador eximir-se da responsabilidade sobre o sentido de determinados itens lexicais e, por fim, como questionamento do efeito de sentido evocado pelas palavras aspeadas.

Palavras chave: Interdiscurso; Heterogeneidade(s) Enunciativa(s); Discurso Indigenista Abstract:

This paper aims to problematize the emergencies of enunciative heterogeneity (AUTHIERRÉVUZ, 1990, 1998, 2004) in the Documento Base prepared to support the $1^{\text {a }}$ Conferencia Nacional de Política Indigenista. It is based on the studies of AD of French origin and on the archegenealogical method (FOUCAULT, 2015), in its dicursivo-deconstructive perspective (CORACINI, 2007, GUERRA, 2011). The results indicate that the use of quotation marks in the analyzed discursive materiality was given first as a preventive resource against the appropriation of the idea of others, then the need for the enunciator subject to exonerate himself from the responsibility about the meaning of certain lexical items and, for end, as questioning the effect of meaning evoked by the aspired words.

Keywords: Interdiscourse; Heterogeneity Enunciative; Indigenous Discourse

\footnotetext{
${ }^{1}$ Doutoranda junto ao Programa de Pós-Graduação em Letras da Universidade Federal de Mato Grosso do Sul. E-mail: sheilabispo2014@gmail.com

${ }^{2}$ Docente permanente do Programa de Pós-Graduação em Letras da Universidade Federal de Mato Grosso do Sul. E-mail: vguerra1@ @erra.com.br.
} 


\section{Introdução}

Por meio de Decreto de 24 de julho de 2014, a então presidente Dilma Roussef convocou a $1^{\text {a }}$ Conferência Nacional de Política Indigenista, um evento que seria realizado pelo Ministério da Justiça e pela Fundação Nacional do Índio - FUNAI - em novembro de $2015^{3}$, com o tema A relação do Estado brasileiro com os povos indígenas no Brasil sob o paradigma da Constituição de 1988, que tinha como objetivos:

I. Avaliar a ação indigenista do Estado brasileiro;

II. Reafirmar as garantias reconhecidas aos povos indígenas no País; e

III. Propor diretrizes para a construção e consolidação da política nacional indigenista. (BRASIL, 2014)

Ainda neste decreto, ficou estabelecido pela presidente que a organização do evento estaria sob a responsabilidade do Ministério da Justiça, da FUNAI em conjunto com representantes dos povos indígenas e demais órgãos e entidades que compõem a Comissão Nacional de Política Indigenista (1CNPI) ${ }^{4}$; cuja etapa nacional seria antecedida pelo Seminário de Formação e por etapas locais e regionais, cada um deles com suas características próprias.

A Comissão Organizadora elaborou o Documento Base que foi utilizado durante as atividades das etapas regionais e nacional da $1^{\mathrm{a}}$ Conferência Nacional de Política Indigenista, e é sobre a constituição discursiva deste documento que gostaríamos de refletir. Antes, porém, gostaríamos de mobilizar uma visão panorâmica da estrutura do documento.

O Documento Base é dividido em quatro partes: 1. Apresentação: Sobre a Conferência; 2. Introdução: Panorama Histórico; 3. Eixos temáticos da $1^{\text {a }}$ Conferência Nacional de Política Indigenista e 4. Conclusão.

A parte Apresentação: sobre a Conferência traz a definição de Conferência e os objetivos da mesma. A Introdução: Panorama Histórico traz um texto e aliado a ele uma linha do tempo da política indigenista brasileira desde o início da Colonização até 2015, ano de realização da Conferência. A parte Eixos temáticos da $1^{a}$ Conferência Nacional

\footnotetext{
${ }^{3}$ Posteriormente, por meio do Decreto de 20 de novembro de 2015, a realização da $1{ }^{\text {a }}$ Conferência Nacional de Política Indigenista foi transferida para o período de 14 a 17 de dezembro de 2015.

${ }^{4}$ A Comissão Nacional de Política Indigenista foi criada por decreto presidencial em 22 de março de 2006, pelo então presidente Luiz Inácio Lula da Silva e foi composta pelos seguintes órgãos e entidades governamentais e não governamentais: Ministério da Justiça, Casa Civil da Presidência da República, Secretaria Geral da Presidência da República, Gabinete de Segurança Institucional da Presidência da República, Ministério de Estado de Minas e Energia, Ministério de Estado da Educação, Ministério de Estado do Meio Ambiente; Ministério de Estado do Desenvolvimento Agrário, Ministério de Estado do Desenvolvimento Social e do Combate à Fome; Ministério do Planejamento, Orçamento e Gestão; representantes indígenas e representantes de ONGs indigenistas.
} 
de Política Indigenista traz os seis temas que foram discutidos em todas as etapas da Conferência, a saber: I. Territorialidade e o direito territorial dos povos indígenas; II. Autodeterminação, participação social e o direito à consulta; III. Desenvolvimento sustentável de terras e povos indígenas; IV. Direitos individuais e coletivos dos povos indígenas; V. Diversidade cultural e pluralidade étnica no Brasil e VI. Direito à memória e à verdade. Finalizando o documento, temos a conclusão.

Neste texto nos debruçamos sobre a problematização das emergências de heterogeneidade(s) enunciativa(s), especialmente na Introdução do Documento Base. Para alcançarmos este objetivo, valemo-nos do método arquegenealógico focaultiano (FOUCAULT, 2015), em sua perspectiva dicursivo-desconstrutiva (CORACINI, 2007, GUERRA, 2011). Segundo essa perspectiva, os acontecimentos discursivos são opacos e podem ser desconstruídos para fazer emergir sentidos produzidos na relação da materialidade com as condições de produção. Tratamos, assim, o Documento Base como um acontecimento discursivo e propusemo-nos a identificar e analisar as diferentes formações discursivas presentes no fio do discurso para realizar nosso gesto de interpretação autorizado pelos fios discursivos entrelaçados na constituição da materialidade.

Nessa visada, a análise de um campo discursivo busca compreender o enunciado em sua singularidade de acontecimento (FOUCAULT, 1987, p. 31), procurando elucidar as condições de sua emergência e estabelecendo relações com outros discursos. Um enunciado é sempre acontecimento, uma vez que abre espaço para sua inscrição na memória já que é suscetível de repetição, transformação e reativação, sobretudo porque está ligado ao interdiscurso, ou seja, a outros enunciados que vieram antes e depois dele ou, no dizer de Orlandi (2009, p. 30): "aquilo que fala antes, em outro lugar, independentemente".

\section{A(s) heterogeneidade(s) enunciativa(s) numa perspectiva discursiva}

A Heterogeneidade se refere, à característica dos discursos de possuírem em seu interior diversas vozes, ora concordantes, ora conflitantes. Existem diferentes maneiras de essas vozes serem representadas. Por vezes elas podem ser claramente notadas, já que o sujeito enunciador as coloca em destaque; em outras, elas estão tão indistintamente envolvidas no fio do discurso e podem passar despercebidas a um leitor desatento. 
Jaqueline Authier-Révuz (1990, 1998, 2004) dedicou-se a estudar a(s) heterogeneidade(s) enunciativa(s), baseando-se nas teorias do Círculo de Bakhtin e também em Lacan. Nesses estudos, ela concluiu que existem quatro não-coincidências do dizer, ou seja, quatro tipos de heterogeneidades, a saber a não-coincidência interlocutiva entre os dois co-enunciadores; a não-coincidência do discurso consigo mesmo, afetado pela presença em si de outros discursos; a não-coincidência entre as palavras e as coisas; e a não-coincidência das palavras consigo mesmas, afetadas por outros sentidos, por outras palavras, pelo jogo da polissemia, da homonímia etc. (AUTHIER-RÉVUZ, 1998). A este trabalho interessa, particularmente, a não coincidência do discurso consigo mesmo.

Dentro do domínio daquilo que a autora chamou de discurso relatado ela diferenciou os conceitos de Heterogeneidade Mostrada e Heterogeneidade Constitutiva, muito esclarecedores para o entendimento do modo como o discurso do outro dialoga com o interlocutor no fio de seu discurso. Segundo Authier-Révuz (2004) "no fio do discurso que, real e materialmente, um locutor único produz, um certo número de formas, linguisticamente detectáveis no nível da frase ou do discurso, inscrevem, em sua linearidade o outro" (p. 12). A essas formas "linguisticamente detectáveis" da presença do outro no discurso, Authier-Révuz $(1990,2004)$ chamou de heterogeneidade mostrada e as dividiu em heterogeneidade mostrada marcada (explícita) e não-marcada.

Como exemplos de Heterogeneidade Mostrada Marcada ou Explícita, temos o discurso direto, no qual as próprias palavras do outro ocupam o tempo e o espaço, e o indireto, no qual o sujeito enunciador atua como tradutor das ideias desse outro. Uma forma mais complexa de heterogeneidade mostrada explícita são as formas marcadas de conotação autonímica, nas quais a marcação é realizada pelas aspas, pelo itálico ou mesmo pela entonação, acompanhados ou não de comentários que representam momentaneamente a voz de outra figura. Existem ainda algumas formas de controleregulagem do processo de comunicação presentes no discurso, como por exemplo, glosas que identificam ou até mesmo traduzem palavras ou expressões pertencentes a outro idioma ou a outra variedade linguística que não a constituinte do discurso; figuras de dúvida, de hesitação, de retoque ou retificação; com jogos sutis ou confirmações; de tentativa de concordância com o interlocutor; instruções sobre a maneira de interpretar o elemento referido; identificadores de pertencimento das palavras ou expressões.

Como formas de heterogeneidade mostrada não-marcada podemos apontar o discurso indireto livre, a ironia, a antífrase, a imitação, a alusão, a reminiscência e o 
estereótipo. Essas últimas não são marcadas no discurso e só podem ser interpretadas levando-se em consideração índices recuperáveis no discurso em função do seu exterior.

A Heterogeneidade Mostrada seria como se o sujeito fosse tomado por uma lembrança súbita da heterogeneidade constitutiva de todo discurso, delimitando claramente a posição de alteridade existente. Para Jaqueline Authier-Révuz (2004), o que diferencia a Heterogeneidade Constitutiva da Heterogeneidade Mostrada é o fato de a primeira não poder se pautar em aspectos linguísticos como o faz a segunda. A Heterogeneidade Constitutiva, segundo ela, se relaciona ao esquecimento $\mathrm{n}^{\circ} 1$, ou seja, o sujeito "esquece" que o sentido se forma em um processo que lhe é exterior e, portanto, coloca-se na origem do dizer, ele "nega" a existência de outras vozes, como se tudo que dissesse fosse original, de modo que não existem marcas linguísticas da presença do outro, apesar do fato de o fio do discurso estar todo entrelaçado por discursos outros.

Para essa autora, "todo discurso se mostra constitutivamente atravessado pelos "outros discursos" e pelo "discurso do Outro". O Outro não é um objeto (exterior, do qual se fala), mas uma condição (constitutiva, para que se fale) do discurso de um sujeito falante que não é a fonte primeira desse discurso. (AUTHIER-RÉVUZ, 2004, p.69)

Quando o sujeito enunciador utiliza formas marcadas de representação do Outro em seu discurso, de certa forma ele quer demonstrar que tudo o que não se apresentou por meio de citações, glosas ou qualquer outra forma de Heterogeneidade Mostrada tem origem em si, negando inconscientemente o diálogo existente entre o já-dito e seu discurso, ou seja, negando que o sentido de seu discurso foi constituído exteriormente a ele. Assim, a Heterogeneidade Constitutiva relaciona-se diretamente com o interdiscurso, ou seja, a "um conjunto de unidades discursivas (que pertencem a discursos anteriores do mesmo gênero, de discursos contemporâneos de outros gêneros, etc.) com os quais um discurso particular entra em relação implícita ou explícita" (CHARAUDEAU e MAINGUENEAU, 2008, p.286).

Partindo desses pressupostos teóricos, nos debruçamos sobre o texto oficial a fim de desenvolver nosso gesto de interpretação a respeito da recorrente utilização das aspas na Introdução do Documento Base da 1CNPI. 


\section{O processo analítico em bases desconstrutivas}

A Introdução do documento oficial analisado é subdividida em seis partes ${ }^{5}$, a saber: 1. A disputa pelo controle da mão de obra indígena nos primeiros séculos da Colônia; 2. O projeto "civilizatório" de assimilação; 3. A expropriação territorial indígena na transição da Colônia para o Império; 4. A institucionalização do regime tutelar na República; 5. As revelações do Relatório Figueiredo e a nova agência indigenista; e 6. O Movimento Indígena, a CF/88 e o Fim da Tutela. Os títulos dos subitens, assim como o subtítulo da Introdução: "Panorama Histórico", nos permitem formular a hipótese de que o objetivo da parte introdutória do documento tenha sido traçar um panorama histórico da política indigenista no Brasil desde a chegada dos colonizadores portugueses a essas terras. Hipótese que pode ser confirmada pela presença de uma Linha do Tempo da Política Indigenista no Brasil, como elemento integrante dessa parte do documento.

A formação discursiva histórica é predominante no texto, mas podemos mostrar traços também das formações discursivas jurídica (legislação/ decretos/ lei/ alvará, por exemplo), bélica (aliados/ inimigos/ guerreiros/ guerras/ ataques/ resistência/ revolta/ cativeiros etc.), religiosa (cristãos/ catequese/ missionários/ jesuítas/ordens religiosas, entre outros), colonial (projeto colonial/ colonos/ sistema colonial/ metrópole, etc.) e capitalista (mão de obra/ atividade comerciais/ pressões comerciais, por exemplo.).

Nos vinte e oito parágrafos que constituem as seis partes da Introdução, as aspas foram utilizadas quarenta vezes, o que caracteriza uma regularidade que saltou aos nossos olhos de analista do discurso e nos incitou a olhar com mais cuidado para os motivos que geraram a necessidade da utilização desse recurso linguístico, ou, segundo Authier-Révuz (2004) dessas negociações entre o sujeito enunciador e a Heterogeneidade Constitutiva.

Nenhum discurso é original, mas se constitui na relação com o interdiscurso. Em outras palavras, todo discurso, independentemente das possíveis marcações realizadas pelos sujeitos enunciadores, é constituído por diferentes vozes, por diferentes discursos, ou seja, é heterogeneamente constituído (AUTHIER-RÉVUZ, 1998). As aspas marcam o discurso do outro, uma das possibilidades de marcação da heterogeneidade mostrada, o

\footnotetext{
${ }^{5}$ Antes do primeiro subitem existe uma parte Introdutória que foi analisada em: BISPO, S.C.M.; GUERRA, V.M.L.O discurso indigenista da Fundação Nacional do Índio: Uma reflexão sobre a criação discursiva da representação do sujeito indígena; no prelo.
} 
que não significa dizer que o que não está marcado por elas não seja também constituído pelo discurso do outro.

Nessa esteira, no Recorte 1, podemos entender a utilização das aspas como a necessidade de marcar o discurso do outro com a finalidade de não se apropriar da ideia alheia. Somos levados a essa interpretação pela citação da fonte nos moldes exigidos pelos textos científicos, com o ano da publicação e o número da página de onde o excerto foi retirado. Vejamos:

R1- "As décadas de 70 e 80 foram os momentos de maior visibilidade dessa modalidade de ação política [o 'movimento indígena' $]$, que se constituía à margem da política indigenista oficial, opondo Estado e sociedade civil, delineando, progressivamente, novas modalidades de cidadania indígena" (Oliveira \& Freire, 2006: 1870). Souza Lima nota que se desenhou, "assim, aquele que é o elemento a questionar mais fortemente as tradições de conhecimento de nosso arquivo colonial: se povos indígenas isolados reivindicaram sempre medidas do Estado e denunciaram [crueldades], a partir desse momento delineia-se no Brasil uma articulação entre povos distintos, e configura-se um movimento indígena, onde o porta-voz branco, tutor seja oficial ou não, deve ser ultrapassado e dar curso à polifonia indígena em nosso país" (SOUZA LIMA, 2010:34) .(FUNAI, 2015, p.18, grifos nossos)

Importante salientar que, apesar das informações constantes no corpo do texto, não é possível confirmar as fontes ou obter mais detalhes a respeito dos temas tratados pelos autores abordados porque o documento não traz Referências, de modo que o sobrenome dos autores, o ano de publicação e o número da página não conseguem nos levar à obra citada. Por que então gastar tempo em adicioná-las ao texto? A aparência do rigor estrutural do texto científico pode ser a busca pelo argumento de autoridade que confere maior credibilidade às informações veiculadas.

Em R1 temos um parágrafo inteiro constituído por citações de diferentes autores, constituído como uma colcha de retalhos que traz como originais apenas as linhas que ligam os retalhos, que no texto se caracterizam como poucas palavras de ligação. Seria a necessidade de não se responsabilizar pelo dito? A utilização das aspas em R1, além de funcionar como prevenção contra a apropriação da ideia alheia, se caracteriza como “aspas de proteção" (AUTHIER-RÉVUZ, 2004, p. 224), que tem a finalidade de frustrar preventivamente a ofensiva do outro. Considerando que o texto trata da exclusão do portavoz branco, que desde 1968 foi oficialmente a FUNAI, por sua incapacidade de dar voz às reivindicações e denúncias dos povos indígenas, podemos interpretar que a citação 
tenha sido utilizada para eximir-se de assumir sua incompetência e fazê-lo pela voz do outro, o que poderia ter um peso menor, poderia ser tomado como uma acusação infundada, poderia permitir uma réplica.

Entendemos que as aspas sejam dispositivos do poder dos discursos hegemônicos, uma vez que elas vêm tentar legitimar, autorizar o que foi feito pela sociedade branca em relação aos povos indígenas no Brasil. Com a colonização, os portugueses abriram caminho para o interior e nesse movimento tampouco pouparam pólvora. Os indígenas eram apagados do mapa. Depois, com a chegada dos imigrantes, novamente os indígenas passaram por violentas levas de extermínio. O tempo passou e as comunidades indígenas que sobreviveram foram travando suas lutas. Houve páginas memoráveis de resistência. $\mathrm{Na}$ região norte, de mais difícil penetração, muitos grupos conseguiram seguir com suas vidas. Mas, no início do século XX, com a nova política de ocupação nacional, os indígenas voltaram a ser contatados, dessa vez com menos violência física, mas com o mesmo intuito de negação da sua cultura e do seu modo de vida. A proposta era a de integrá-los à vida nacional, considerada "a civilização". Ninguém perguntou aos indígenas se era esse o seu desejo. Era uma política de Estado e estava baseada na ideia de que o modo originário de vida não era bom (GUERRA, 2015).

Todas essas lutas sempre se deram num contexto desigual. Primeiro, os indígenas eram os selvagens que precisavam ser civilizados, depois eram os preguiçosos que não queriam saber de trabalhar no mundo novo que tão bondosamente tinha sido dado a eles. De um jeito ou de outro eram apresentados à nação como seres inúteis, passíveis apenas de se manterem como "coisa exótica". Quando essas comunidades começaram a lutar, outra vez, pelos seus territórios, toda essa carga de preconceito voltou à tona. E os indígenas passaram a ser apontados como aqueles que impediam o progresso do país. Garantir grandes extensões de terra a esses povos era visto como um absurdo, afinal, eles não trabalhavam: tal e qual os portugueses de 1500, os governantes seguiam olhando para os indígenas como seres de segunda categoria, incapazes, obstáculos, que deviam ser aniquilados.

Segundo a portuguesa Karhen Lola Profírio Will (2016), em seu estudo sobre o genocídio indígena no Brasil, o governo faz propaganda e usa dos meios de comunicação mentindo descaradamente sobre diálogo e promoção de direitos indígenas. Mas, na prática, a política segue sendo a do extermínio e do massacre das culturas autóctones. Na contramão de tudo o que acontece na América Latina, aonde os povos originários vão conquistando cada dia mais direitos, o governo brasileiro caminha para o retrocesso, 
aliado ao agronegócio e aos interesses internacionais, jogando o povo inteiro nas malhas da eterna dependência. Para esses povos, a terra não é objeto de especulação, é espaço sagrado. Terra é mãe da vida, água é morada dos deuses, animais são parte de um equilibrado sistema de sobrevivência que não tem preço, mas valor.

Prosseguindo o processo analítico, entendemos que a presença das aspas como prevenção contra a apropriação da ideia alheia não é a forma mais presente de sua utilização no texto analisado. Com base em R2, discorremos sobre as aspas usadas como marcas de distanciamento (AUTHIER-RÉVUZ, 2004).

R2 - A consequência imediata do Diretório dos Índios $^{6}$ foi o afastamento das missões religiosas e a expulsão dos jesuítas da colônia, alterando a administração dos povos indígenas e reorganizando os aldeamentos, que foram transformados em vilas com nomes de sítios e freguesias de Portugal. O Diretório foi um plano de assimilação forçada e de "civilização" imposta, por meio do qual se pretendeu atribuir aos índios a condição de súditos da coroa portuguesa - num contexto de enorme desigualdade, no qual a escravidão indígena ainda era comum. A "civilização" dos índios seria realizada em escolas públicas, ondes lhes seriam ensinados ofícios domésticos e para subsistência. Estabeleceu-se a obrigatoriedade do uso da língua portuguesa pelos povos colonizados, sendo que os "índios civilizados" deveriam ganhar nomes e sobrenomes como em Portugal. Foram conferidos prêmios aos colonos que se casassem com mulheres indígenas. Os índios passaram a ser administrados por juízes e vereadores, o que os igualava - apenas formalmente - aos demais súditos. Determinou-se que os "principais" indígenas governassem as "vilas de índios" e, nas situações em que não tivessem capacidade de fazê-lo (seja devido à ignorância ou à falta de aptidão - segundo o ponto de vista dos colonizadores), estabeleceramse "diretores de índios" nas povoações, com domínio da língua indígena, que deveria perseguir esses fins. (FUNAI, 2015, p. 11, grifos nossos))

Em R2, diferentemente do que se apresentou em R1, e como exemplo do que se realizou em várias outras utilizações das aspas na Introdução do Documento Base, as aspas não foram utilizadas para marcar sentenças ou períodos atribuídos a outros enunciadores e acompanhadas das informações de quem as produziu, mas servem para destacar palavras e expressões das quais o sujeito enunciador pretende se distanciar, colocar em suspensão de responsabilidade (AUTHIER-RÉVUZ, 2004), pelo efeito de sentido que podem suscitar no interlocutor a quem o texto de dirige.

Considerando a premissa de que todo discurso é dirigido a um interlocutor (AUTHIER-RÉVUZ, 1998), podemos, em uma primeira leitura, interpretar que este

\footnotetext{
${ }^{6}$ Em 1755 foi aprovado o Diretório dos Índios, que proibia definitivamente a escravidão indígena e visava a integração do índio à vida da Colônia.
} 
discurso se dirige aos povos indígenas, participantes da 1CNPI, mas, com um olhar mais atento, podemos entender que os principais interlocutores são os órgãos internacionais como a Organização Internacional do Trabalho e a Organização das Nações Unidas a quem interessa agradar para a obtenção de uma boa imagem internacional que possa vir a gerar investimentos e capital político relevante. Tanto para os primeiros como para os últimos, os itens lexicais aspeados (“civilização", "índios civilizados", "vilas de índios", "principais", "diretores de índios”), poderiam suscitar um estranhamento e mesmo uma rejeição ao texto do documento. Isso porque esses termos se relacionam diretamente ao campo semântico da Integração, que durante muitos anos foi propalada por documentos oficiais brasileiros e objetivava gradativamente o desaparecimento dos indígenas por sua conversão a brasileiros. "Integração" essa rejeitada pelos movimentos indígenas e por todos os interessados pelas causas indígenas. Logo, as aspas permitem passar a ideia de distanciamento do sujeito enunciador a essas palavras, e criar a ilusão de que elas só foram utilizadas por falta de outras que pudessem ser empregadas em seu lugar, ou porque essas são as escolhas lexicais permitidas pela formação discursiva histórica que predomina no documento.

A "integração", assim como todas as palavras que fazem parte de seu campo semântico constroem a ideia de ausência, de incompletude, de falta de civilização. Segundo o dicionário Michaelis On Line ${ }^{7}$, um dos sentidos atribuídos ao item lexical civilização é “ato, processo ou efeito de civilizar(-se)". Se é necessário civilizar-se é porque não se é civilizado, logo, o sujeito enunciador, com a utilização das aspas, atribuiu esse sentido à palavra civilização em seu discurso, sentido ao qual o interlocutor avesso à integração pode considerar negativamente, por considerar os povos indígenas civilizados. Esse sentimento de civilização, de completude cultural é referendado pelos demais sentidos atribuíveis à palavra civilização, a saber: "2. Conjunto de aspectos próprios da vida social, intelectual, artística, cultural, econômica, política e moral de uma sociedade; 3. Estágio de desenvolvimento econômico, científico e tecnológico de uma sociedade; 4. Conjunto de valores que caracterizam uma sociedade; tipo de cultura". Todas as comunidades indígenas possuem vida social, intelectual, artística, cultural, econômica, científica e tecnológica, além de valores, em diferentes níveis de desenvolvimento, de modo que todas as comunidades indígenas são civilizadas e não necessitam de nenhum ato ou processo de civilização.

\footnotetext{
${ }^{7}$ http://michaelis.uol.com.br/moderno-portugues/ Acessado em 12 de abril de 2018 às 8 h.
} 
O que se traduziu no discurso analisado como civilização seria na verdade aculturação, que, segundo o mesmo dicionário, significa: “1. Adaptação de um indivíduo ou de um grupo a uma cultura diferente com a qual mantém contato direto e contínuo, aculturamento; 2. Conjunto de fenômenos resultantes do contato direto e contínuo entre pessoas de culturas diferentes." No entanto, essa adaptação não aconteceria respeitando a condição entre-culturas dos povos indígenas, ao que Canclini (2013) denominou de hibridação intercultural, ou ao que Hall (2006) chamou de multiculturalismo, e sim no sentido se subjugação cultural, de rejeição à cultura original, considerada menor, e mudança, transferência para a cultura do colonizador, considerada superior, nos moldes daquilo que os estudos pós-colonialistas rejeitam (SANTOS, 2010; NOLASCO, 2016).

A busca pelo domínio cultural pode ser comprovada se desviarmos nossos olhos das palavras aspeadas para outras que compõem o mesmo parágrafo. Segundo R2, o Diretório de Índios tinha a intenção de estabelecer moldes para a relação entre brancos e índios proibindo a escravidão, mas "permitindo" alterar, reorganizar, atribuir, ensinar, obrigar...

Qual seria a justificativa para que um documento permitisse aos brancos tomar atitudes como as descritas pelos verbos destacados que influenciariam diretamente na disposição cultural indígena? "Alterar a administração"; "reorganizar os aldeamentos"; "atribuir a condição de súditos da coroa"; "ensinar ofícios domésticos e para subsistência"; "obrigar o uso da língua portuguesa"...

Parece que até a chegada dos portugueses ao Brasil os indígenas não tinham uma organização que lhes permitisse viver, se comunicar, se alimentar, subsistir. Parece que era necessário lhes ensinar tudo, era necessário que passassem por um processo "civilizatório". Com isso podemos problematizar que, apesar de o sujeito enunciador tentar cercar o sentido de palavras que pudessem causar no interlocutor rejeição, outros itens lexicais não aspeados denunciam a heterogeneidade constitutiva do discurso, sua relação com o interdiscurso da formação discursiva colonialista segundo a qual a superioridade europeia é estabelecida como se não houvesse outra possibilidade existente (QUIJANO, 2010). Essa superioridade se mostra ainda em outras situações descritas no recorte analisado como na possibilidade de o branco "conferir prêmios" a outros brancos que se disponibilizassem a casar com mulheres indígenas, ou na possibilidade de conceder aos indígenas o direito de se "igualar" aos brancos, ainda que apenas formalmente. 
Consideramos que, apesar de o Documento Base não ter sido desenvolvido pela FUNAI, mas por uma Comissão Organizadora Nacional composta por representantes de órgãos governamentais, representantes indígenas e representantes de organizações indigenistas não governamentais, tanto a composição da comissão ${ }^{8}$ como a divulgação do documento em sites oficiais ${ }^{9}$ nos permitem interpretar que o discurso veiculado se caracteriza como discurso oficial, construído com bases nas diretrizes governamentais para a política indigenista brasileira. Partindo desse pressuposto, podemos problematizar que as aspas foram utilizadas porque as palavras utilizadas são apropriadas ao sujeito enunciador, mas não ao sujeito interlocutor no sentido de que se o enunciador estivesse dirigindo o seu discurso para outros interlocutores que não os povos indígenas ou aos órgãos internacionais envolvidos com a questão indígena elas seriam desnecessárias. ("Se eu não falasse com você, eu o diria sem aspas”. (AUTHIER-RÉVUZ, 2004, p.221).

Nessa discussão dos dados, em R3, temos uma motivação diversa de R1 e R2 para a utilização das aspas:

R3- Rondon e outros propuseram a criação de uma agência indigenista laica cuja ação teria por fins: a) estabelecer a convivência pacífica com os índios; b) garantir a sobrevivência física dos povos indígenas; c) fazer os índios adotarem gradualmente hábitos "civilizados"; d) influir de forma "amistosa" sobre a vida indígena; e) fixar o índio à terra; f) contribuir para o povoamento do interior do Brasil; g) acessar ou produzir bens econômicos nas terras dos índios; h) usar a força de trabalho indígena para aumentar a produtividade agrícola; e i) fortalecer o sentimento indígena de pertencer a uma nação. A "proteção fraternal", defendida pelo grupo rondoniano contra as posições favoráveis ao extermínio puro e simples dos índios, criaria as condições adequadas para a evolução lenta e natural deles rumo à civilização." (FUNAI, 2015, p. 13, grifos nossos))

R3 foi retirado de um subitem intitulado $A$ institucionalização do regime tutelar na República e trata diretamente das diretrizes de criação do Serviço de Proteção aos Índios e Localização de Trabalhadores Nacionais (SPILTN), em 1910. Posteriormente, em 1918, houve uma separação no órgão criando-se o Serviço de Proteção aos Índios (SPI).

\footnotetext{
${ }^{8}$ Importante salientar que a constituição da Comissão Organizadora Nacional da 1CNPI foi elaborada para que o discurso governamental sempre fosse prevalente, uma vez que mesmo todos os representantes indígenas somados aos representantes das organizações não-governamentais (12 votos) não conseguiriam derrubar uma proposta governamental por ter sido garantida a maioria de representantes de órgãos governamentais (13 votos).

${ }^{9}$ Primeiramente no site da 1CNPI (www.conferencianacionaldepoliticaindigenista.funai.gov.br), retirado do ar em setembro/2017 e, posteriormente no site da FUNAI (http://www.funai.gov.br/index.php/todospresidencia/3252-documentos-1-conferencia-nacional-de-politica-indigenista).
} 
Em R3 as aspas foram utilizadas três vezes. Os dois primeiros aspeamentos se deram apenas nos adjetivos "civilizados" e "amistosa". O adjetivo tem a função de modificar o substantivo com o qual se relaciona. No recorte analisado, o adjetivo civilizados se relaciona ao substantivo hábitos e o adjetivo amistosa se relaciona ao substantivo forma, de modo que, para a constituição de nosso movimento interpretativo consideramos as expressões hábitos civilizados e forma amistosa. Na terceira utilização do recurso linguístico das aspas pelo sujeito enunciador em R3, substantivo e adjetivo foram aspeados: "proteção fraternal".

Diferentemente da utilização das aspas em R1, quando se precavia quanto à apropriação da ideia alheia, ou em R2 quando o sujeito enunciador procurava não se responsabilizar pelo efeito de sentido que os itens lexicais aspeados poderiam fazer emergir em seus interlocutores, em R3 as aspas nos conduzem ao que Authier-Révuz (2004) chamou de questionamento do caráter apropriado de uma palavra.

Nessa esteira, o que seriam "hábitos civilizados" com base naquilo que já discutimos longamente a respeito do que seria civilização? Certamente o que o Serviço de Proteção ao Índio (SPI) buscava era a adaptação dos povos indígenas ao modo de vida dos brancos e consequentemente a seus hábitos, contudo a utilização do adjetivo "civilizados" não nos parece adequada, considerando que toda sociedade possui hábitos e valores que correspondem à sua civilização. Assim, o sujeito enunciador o marca com aspas para não desencadear um conflito com o interlocutor.

Da mesma maneira, o que seria 'influir de forma 'amistosa' sobre a vida indígena"? Trabalhar institucionalmente para transformar os povos indígenas em brasileiros, buscando mudar seus hábitos, costumes e valores; desvalorizando sua língua materna; poderíamos considerar isso uma influência "amistosa"? Mais uma vez o sujeito enunciador parece entender que o termo utilizado não seria o mais adequado para tratar da real influência que, historicamente, se estabeleceu entre os brancos e os povos indígenas. Mais uma vez, o enunciador utiliza-se do recurso linguístico que tem à sua disposição para marcar que essa qualificação não foi atribuída por ele, mas faz parte do interdiscurso, da memória discursiva das relações entre brancos e indígenas.

Por fim, problematizamos que a terceira utilização das aspas em R3 também se deu pela necessidade de marcar o discurso do outro pelo entendimento da inadequação dos itens lexicais. Historicamente não podemos dizer que os brancos exerceram uma “proteção fraternal” com os povos indígenas. 
"Hábitos civilizados", "influência amistosa", "proteção fraternal”... Considerando a relação estabelecida não apenas no Brasil, mas em todo o processo de colonização da américa pelos europeus, podemos afirmar que o colonizador não reconheceu as culturas dos povos originais, questionando até mesmo sua humanidade e, para realizar a repressão cultural e a colonização do imaginário, realizou um gigantesco e violento extermínio dos povos indígenas. As questões etnocêntricas justificaram tal genocídio que teve como resultado a transformação de altas culturas em culturas iletradas. Aos sobreviventes a esse extermínio não restou outra alternativa que não se submeter aos padrões dos dominadores (QUIJANO,1992, FLEURI, 2002).

No Brasil não foi diferente, também aqui os povos indígenas sofreram com a perseguição, a escravização e a dizimação de suas populações. Em 1500, a população estimada era de 3 milhões de indígenas e decresceu até alcançar, na década de 50 do século XX, a população de 70 mil sujeitos indígenas. Essa tendência de queda foi revertida a partir dos anos 1980 e no censo de 2010 o Instituto Brasileiro de Geografia e Estatística apurou a população de 817.962 indígenas. Esse crescimento não se deve apenas a aspectos demográficos, ou seja, a mortalidade, natalidade e migração, mas especialmente ao crescimento do número de pessoas que se reconheceram como indígenas (IBGE).

A colonização não gerou apenas a drástica diminuição da população indígena, mas, diante da heterogênea realidade linguística que dificultava as intenções econômicas e religiosas dos colonizadores, levou à busca da homogeneização linguística com a adoção das línguas gerais, o que perdurou de 1549 a 1759, durante o período em que os jesuítas permaneceram no Brasil. Nesse período, a língua tupi foi institucionalizada como língua hegemônica, o que resultou em sua imposição para grupos não-tupis, como estratégia de dominação e ocupação territorial (BORGES, 2001). A utilização das línguas gerais adquiriu tamanha abrangência que, especialmente na região Norte, a língua portuguesa aos poucos foi ficando confinada apenas aos redutos da nobreza. Por esta razão, o Marquês de Pombal, ao realizar uma reforma pedagógica em Portugal e no Brasil, torna oficialmente obrigatórios o ensino e a utilização da língua portuguesa (MARIANI, 2001).

Logo, se considerarmos que antes da chegada dos portugueses existiam no território brasileiro cerca de 1175 línguas (NOBRE, 2011), e que tanto pelo extermínio de grande parte da população indígena como pelas políticas linguísticas adotadas desde o 
início da colonização a maior parte delas foi extinta; ${ }^{10}$ e se também considerarmos a intrínseca relação existente entre língua e cultura, poderemos compreender como a dizimação da população e a colonização cultural gerada pela imposição da língua, da religião e dos costumes dos colonizadores fizeram com que os povos indígenas brasileiros estivessem culturalmente posicionados no entremeio entre a cultura tradicional indígena e a cultura branca, ou seja, numa situação de transculturação (GUERRA, 2015).

Com base em nosso gesto de interpretação a respeito da materialidade discursiva analisada, o sujeito enunciador, no entendimento da incompatibilidade dos itens lexicais com a memória discursiva relativa ao modo como se operou a relação entre brancos e indígenas aspeou palavras que pudessem ter seu sentido questionado com o intuito de passar a ideia de que foi ele o primeiro a questionar o caráter inapropriado de sua utilização; de que, apesar de aqueles itens lexicais estarem presentes em seu discurso eles não são originárias dele, mas são o discurso do outro presente em seu discurso.

Nessa tensa relação entre o interior e o exterior do discurso, partindo da crença de que tudo o que não estivesse marcado no discurso fosse originado em si, o enunciador passa por lapsos e deixa de marcar mais palavra/expressões que também precisam ter seu caráter questionado, vejamos: "estabelecer convivência pacífica com os índios", depois de tudo que se discutiu é possível acreditar que houve o estabelecimento de uma convivência pacífica?

"Garantir a sobrevivência física dos povos indígenas". E a sobrevivência cultural? Emocional? Não são relevantes? Segundo o enunciador, caso o SPI conseguisse manter os índios fisicamente vivos teria conseguido alcançar a "convivência pacífica" ou a "proteção fraternal". A ausência da necessidade de aspear tais expressões nos leva a problematizar que essas palavras não geraram estranhamento no sujeito enunciador, de modo que ele não se importou de tê-las atribuídas a si.

"Fixar o índio à terra"? Não seria descabido atribuir essa fixação ao homem branco uma vez que, antes de os colonizadores chegarem, eles já viviam em uma relação plena com a terra, tirando dela seu sustento, seus remédios, sua religião? Pelo contrário, quem impossibilitou a fixação dos povos indígenas foram os brancos que tomaram suas terras e colocaram como condição de permanência que "bens econômicos fossem acessados ou produzidos" e que eles fossem "força de trabalho para aumentar a produtividade agrícola"

${ }^{10}$ Os resultados do Censo 2010 indicam para a existência de 276 línguas indígenas, no entanto, são necessários estudos linguísticos e antropológicos aprofundados para constatar se incluídas nesse total não existem variações de uma mesma língua. (IBGE) 
numa clara violência cultural. "Produtividade", "bens econômicos" não eram importantes para os povos indígenas que não estabeleciam relações comerciais.

Para os indígenas, o importante era a subsistência para a manutenção da qual bastava a caça, a pesca, o extrativismo e a agricultura de itens agrícolas suficientes. A violência cultural que a escravidão e, posteriormente, a inclusão dos povos indígenas como mão de obra pouco valorizada influenciou para a fuga dos povos indígenas e sua considerada "não fixação à terra". A influência do homem branco não contribuiu para sua fixação, pelo contrário, a maior luta dos movimentos indígenas na atualidade continua sendo por demarcação de terras indígenas, por sua fixação à terra de seus ancestrais. Lutas essas que o homem branco continua dificultando por colidir com os interesses econômicos dos grandes latifundiários.

Por fim, ao invés de "fortalecer o sentimento indígena de pertencer a uma nação", o homem branco contribuiu para o enfraquecimento das nações indígenas. A partir desse subitem surge a ideia de "integrar" os indígenas à nação brasileira, fazendo com que esquecessem seu sentimento de pertença à sua nação indígena e a criação de sentimento de pertença à nação brasileira. Como já discutimos, a "integração" é considerada altamente inapropriada pelos povos indígenas e por todos aqueles que se interessam pelas questões indígenas, a saber, ONGs e pesquisadores.

Como observamos, além das três utilizações do recurso linguístico das aspas em R3, haveriam muitas outras ocasiões em que seria necessária a utilização desse recurso caso o sujeito enunciador tentasse cercar todos os itens lexicais/expressões/orações questionáveis em sua apropriação. Em nossa interpretação, essas marcações não ocorreram porque o sujeito enunciador representa o Estado e defende a posição de que sua atuação indigenista foi positiva e contribuiu para a "garantia da sobrevivência física dos povos indígenas"; para a "fixação do indígena à terra"; para o "povoamento do interior do Brasil"; para o "acesso ou produção de bens econômicos nas terras indígenas"; para a "utilização da força de trabalho indígena para o aumento da produtividade agrícola"; para o "fortalecimento do sentimento indígena de pertencimento a uma nação." Entendemos, a partir das palavras de Authier-Révuz (2004), que:

As aspas são, portanto, em um discurso algo como o eco de seu encontro com o exterior. Apesar dos termos interior/exterior, borda, fronteira, esse encontro não se faz segundo uma linha de justaposição, mas na forma de uma zona de interação, de imbricação, de invasão. (p. 229-230) 
Com a linguista afirmamos que as aspas procuram marcar o exterior que está presente no discurso, mas o fazem com imperfeição uma vez que todo o discurso é heterogeneamente constituído. Apesar disso, a imperfeição mostrada por elas é uma imperfeição constitutiva, reveladora da necessária negociação existente nas margens borradas do discurso.

\section{Considerações finais}

O processo analítico aqui empreendido trata de recortes de uma pesquisa intitulada "Uma análise discursivo-desconstrutiva do discurso indigenista oficial brasileiro", que está em andamento junto ao Programa de Pós-Graduação em Letras, do Câmpus de Três Lagoas, da Fundação Universidade Federal de Mato Grosso do Sul, na sua fase inicial.

No estudo realizado neste artigo, buscamos analisar quais os motivos que levaram à necessidade da numerosa utilização do recurso linguístico das aspas na Introdução do Documento Base da 1CNPI, que se revelou como uma regularidade. Com base nos recortes analisados entendemos que houve três elementos desencadeadores: primeiro, a necessidade de marcação do discurso do outro para prevenção contra a apropriação da ideia alheia. Neste caso, os períodos aspeados vinham acompanhados da citação nos moldes dos utilizados em textos científicos, com o sobrenome do autor, seguido do ano de publicação e o número da página de onde o excerto foi retirado, ainda que o Documento Base não conte com Referências.

Uma segunda utilização das aspas foi motivada pela necessidade de o sujeito enunciador eximir-se da responsabilidade sobre o sentido que a utilização de determinado item lexical possa causar no interlocutor. No texto, palavras que remetem à Integração, rejeitada por indígenas e por todos aqueles interessados nas causas indígenas foram marcadas com aspas, a fim de criar a ilusão de que foram utilizadas por não existirem outras palavras permitidas na formação discursiva histórica para se relacionar àquele acontecimento, ou, em uma segunda interpretação possível, pelo fato de o item lexical aspeado ser favorável ao sujeito enunciador mas não aos interlocutores.

Por fim, a terceira motivação para a utilização do recurso linguístico das aspas foi o questionamento do caráter apropriado dos itens lexicais na criação do efeito de sentido permitido pela memória discursiva referente ao relacionamento histórico entre brancos e indígenas. 
Em todas as situações, apesar de o sujeito enunciador tentar "evidenciar" o discurso do Outro no interior do intradiscurso, ocasiões passaram "desapercebidas" e a negociação entre o intradiscurso e o interdiscurso falhou.

\section{Referências}

AUTHIER-RÉVUZ, J. Heterogenidade(s) Enunciativa(s). In: Cadernos de Estudos Linguísticos, nº19, Campinas, jul-dez, 1990.

AUTHIER-RÉVUZ, J. Palavras Incertas: as não-coincidências do dizer. Campinas: Editora da UNICAMP, 1998

AUTHIER-RÉVUZ, J. Entre a transparência e a opacidade: um estudo enunciativo do sentido. Porto Alegre: EDIPUCRS, 2004.

BRASIL. (2014) DECRETO DE 24 DE JULHO DE 2014. Convoca a $1^{\text {a }}$ Conferência Nacional de Política Indigenista. Disponível em: http://www.funai.gov.br/arquivos/ conteudo/ascom/2014/doc/11-nov/decreto.pdf. Acesso em 22/04/2018, às 11h30.

BORGES, Luiz C. A Instituição de Línguas Gerais no Brasil. In: ORLANDI, Eni P. (Org.) História das Ideias Linguísticas do Brasil: construção do saber metalinguístico e constituição da língua nacional. Campinas: Pontes; Cáceres, MT: Unemat Editora, 2001.

CANCLINI, Néstor G. Culturas híbridas: poderes oblíquos. In: Culturas híbridas: estratégias para entrar e sair da modernidade. Trad. Heloisa Pezza Cintrão e Ana Regina Lessa. São Paulo: Editora da Universidade de São Paulo, 2013, p. 283-351.

CHARAUDEAU, P.; MAINGUENEAU, D. Dicionário de Análise do Discurso. São Paulo: Contexto, 2008. 2ed.

CORACINI, Maria J. A celebração do outro: arquivo, memória e identidade: línguas materna e estrangeira. Plurilinguismo e tradução. Campinas: Mercado de Letras, 2007.

FLEURI, Reinaldo Matias. Intercultura e educação. In: Revista Brasileira de Educação, $\mathrm{n}^{\mathrm{o}} 23.2003$.

FOUCAULT, Michel. A Arqueologia do Saber. 3 ed. Trad. Baeta Neves. Rio de Janeiro: Forense Universitária, 1987.

FOUCAULT, Michel. Método. In: FOUCAULT, Michel. História da sexualidade I: a vontade de saber. E ed. Trad. Maria Thereza da Costa Albuquerque e J.A. Guilhon Albuquerque. São Paulo: Paz e Terra, 2015.

FUNDAÇÃO NACIONAL DO ÍNDIO (2015) Documento Base. Disponível em: http://www.funai.gov.br/index.php/todos-presidencia/3252-documentos-1-conferencianacional-de-politica-indigenista. Acesso em 06/11/2017. Acessado em 15/08/2017 às 22 h.

GUERRA, V.M.L. Entre a mídia impressa e o discurso da "integração", a construção identitária dos indígenas. In CORACINI, Maria José R. F. (Org.) Identidades silenciadas e (in)visíveis: entre a inclusão e a exclusão (identidade, mídia, pobreza, situação de rua, mudança social, formação de professores). Campinas: Pontes, 2011, p.127-148. 
GUERRA, V.M.L. Povos indígenas: identidade e exclusão social. Campo Grande: Editora da UFMS, 2015.

HALL, Stuart. A questão multicultural. In HALL, Stuart. Da diáspora: identidades e mediações culturais. Org. Liv Sovik. Trad. Adelaine La Gurdia Resende et al. Belo Horizonte: Editora da UFMG. 2006, p. 51-100.

INSTITUTO BRASILEIRO DE GEOGRAFIA E ESTATÍSTICA. O Brasil indígena. In: http://www.funai.gov.br/arquivos/conteudo/ascom/2013/img/12-Dez/pdf-brasilind.pdf. Acessado em: 15/07/2017 ás $18 \mathrm{~h}$.

MARIANI, Bethania. A institucionalização da Língua. História e Cidadania no Brasil do Século XVIII: O Papel das Academias Literárias e da Política do marquês de Pombal. In: ORLANDI, Eni P. (Org.) História das Ideias Linguísticas do Brasil: construção do saber metalinguístico e constituição da língua nacional. Campinas: Pontes; Cáceres, MT: Unemat Editora, 2001.

NOBRE, Wagner Carvalho de Argolo. Introdução à história das línguas gerais no Brasil: processos distintos de formação no período colonial 2011. 229 f. Dissertação. Universidade Federal da Bahia, Salvador, 2011.

NOLASCO, Edgar C. O método do discurso fronteiriço: por uma aproximação do sujeito da exterioridade. In: GUERRA, V. M.L. ; ALMEIDA,W.D. (Orgs). Povos indígenas em cena: das margens ao centro da história. Campo Grande: OMEP/BR, 2016, p.52-66.

ORLANDI, Eni P. As formas do silêncio no movimento dos sentidos. 7. ed. Campinas: Editora da Unicamp, 2009.

QUIJANO, Aníbal. Colonialidade do poder e classificação social. In: QUIJANO, Aníbal. MENESES, Maria Paula (orgs.). Epistemologias do Sul. São Paulo: Cortez, 2010. P. 84130.

QUIJANO, Aníbal. Colonialidad y Modernidad/Racionalidad. 1992. Disponível em: https://problematicasculturales.files.wordpress.com/2015/04/quijano-colonialidad-ymodernidad-racionalidad.pdf. Acesso em: 29/07/2016.

SANTOS, Boaventura S. Para além do Pensamento Abissal: das linhas globais a uma ecologia dos saberes. In: SANTOS, Boaventura S. MENESES, Maria Paula (orgs.). Epistemologias do Sul. São Paulo: Cortez, 2010. P. 31-83.

WILL, Karhen Lola P. Um retrato do genocídio cultural no campo jurídico internacional. Revista dos Tribunais. Vol. 969. Ano 105. p. 111-130. São Paulo: Revista do Tribunais, jul. 2016.

Data de Recebimento: 03/10/2018

Data de Aprovação: 25/04/2019 


\section{Para citar essa obra:}

BISPO, Sheila da Costa Mota e GUERRA, Vânia Maria Lescano; A emergência das heterogeneidades enunciativas o discurso indigenista oficial brasileiro In: RUA [online]. Volume 25, número 1 - p. 309-327 - e-ISSN 2179-9911 - junho/2019. Consultada no Portal Labeurb - Revista do Laboratório de Estudos Urbanos do Núcleo de Desenvolvimento da Criatividade.

http://www.labeurb.unicamp.br/rua/

Capa: $1^{\mathrm{a}}$ Conferência Nacional de Política Indigenista. Disponível em: https://www.facebook.com/pg/conferencianacionalam/posts/

Laboratório de Estudos Urbanos - LABEURB

Núcleo de Desenvolvimento da Criatividade - NUDECRI

Universidade Estadual de Campinas - UNICAMP

http://www.labeurb.unicamp.br/

Endereço:

LABEURB - LABORATÓRIO DE ESTUDOS URBANOS

UNICAMP/COCEN / NUDECRI

CAIXA POSTAL 6166

Campinas/SP - Brasil

CEP 13083-892

Fone/ Fax: (19) 3521-7900

Contato: http://www.labeurb.unicamp.br/contato 